\title{
Trends in remaining life expectancy at retirement age (65 years) by educational level in Norway 1961-2009
}

\author{
Joakim Oliu Moe ${ }^{1}$, Ólöf Anna Steingrímsdóttir ${ }^{2}$, Bjørn Heine Strand ${ }^{2}$ and Øyvind Næss ${ }^{1,2}$ \\ 1) Department of Health Management and Health Economics, Institute of Health and Society, University of Oslo \\ 2) Division of Epidemiology, Norwegian Institute of Public Health, Oslo, Norway \\ E-mail: j.o.moe@medisin.uio.no
}

\begin{abstract}
Background: Over the last half a century education based inequalities in life expectancy have increased in younger populations, but our knowledge of long-term trends in old-age life expectancy differentials is sparse. We investigated the trends in remaining life expectancy at age $65\left(e_{65}\right)$ according to education in Norway for the period 1961-2009.

Methods: This was a register-based population study including all Norwegian residents aged 65 years and older. Individual-level data were provided by the Central Population Registry and the National Educational Database. We classified education into higher and lower education and constructed one life table for each calendar year, sex, and educational group. We tested for trends using weighted least square regression models. Results: $e_{65}$ increased over the observation period for all educational groups, but the difference in $e_{65}$ increased by 0.060 life years per calendar year in men and 0.025 life years per calendar year in women $(\mathrm{P}<$ $0.001)$. The increase in $e_{65}$ in less-educated men slowed in the $1980 \mathrm{~s}$ and $1990 \mathrm{~s}$, whereas $e_{65}$ in less-educated women decelerated from the 1980s, and significantly so from $2001(\mathrm{P}=0.029)$.

Conclusions: Educational-based inequalities in $e_{65}$ increased over the last half century. The increase seems to be temporal in men and might be ongoing in women. Increasing inequalities in $e_{65}$ challenge public health policy and will become increasingly important in the ageing societies of the future. In addition, they imply increasing deviation from the overall life expectancy of the population, which forms the basis of the recently implemented adjustment of pension levels according to life expectancy. Divergent trends in $e_{65}$ according to educational level may also have implications for future demographic projections.
\end{abstract}

\section{INTRODUCTION}

Western populations are ageing because of their low fertility rates and increasing life expectancies [1]. In the first half of the 20th century, life expectancy increased in response to the large reductions in mortality at younger ages [2]. Whereas mortality eventually became rare in younger age groups, declining mortality among the middle-aged, and later in the elderly, propelled the increase in life expectancy [3,4]. Most people in the Western world today survive to retirement age, and the mean expected retirement duration in OECD countries has increased continuously for several decades [5].

However, these changes have not benefitted everyone equally. Life expectancy at retirement age varies substantially according to socioeconomic determinants like educational level [6], occupation [7] and deprivation levels [8]. Although relative socioeconomic inequalities in mortality diminish with age [9-11], absolute inequalities, which are important to public health policy, increase [11]. Life expectancy is calculated based on mortality rates, and life expectancy differentials sum the absolute mortality rate differences in all age groups above the index age for a specific period. Thus, life expectancy differentials are more directly linked to mortality rate differences than to mortality rate ratios. Furthermore, because mortality rate differences increase with age, inequalities in old-age mortality are most relevant to life expectancy differentials today [4].

Inequalities in health are constantly changing, and educational inequalities in life expectancies have increased in working-aged populations between 1970 and $2000[4,12,13]$. However, we know little about the long-term trends in life expectancy differentials among the aged. Studies of shorter periods, up to two decades, have revealed increasing education-based inequalities in life expectancy at age $65[4,14,15]$. Inequalities in life expectancy at age 65 also seem to have increased according to other socio-economic determinants $[7,8]$.

The increasing proportion of older adults challenges the welfare states in several domains, and particularly in terms of pension systems. One of the challenges has been that politicians needed to base their pension decisions on projections that have repeatedly underestimated future increases in life expectancy $[2,5]$. To ensure the long-term affordability of their pension systems, many OECD countries have therefore recently reformed them [5]. One of the most important innovations of pension policy in recent years has been the automatic adjustment of benefits to life expectancy [5]. Life expectancy adjustments stabilize the finances of the pension system and a government's pension decisions need no longer rely on the uncertain projections of life expectancies [5].

Life expectancy adjustment to the pension system was adopted by Norway in 2011 [5,16]. The Norwegian model uses the combined figures for the life expectancy of the population as a whole. When the cohorts are 61 years old, they are accorded a separate life expectancy factor for all potential retirement ages (be- 
tween 62 and 75). Upon retirement, the annual pension is calculated by dividing the total pension entitlements by the life expectancy factor of the birth cohort for the particular retirement age [5]. This method does not take into account the fact that life expectancies differ within each birth cohort [17]. It ignores the fact that life expectancies differ with sex [13] and with the various social conditions under which people live and age [18]. Whereas the dependence of health on social conditions can be considered as unfair per se [19,20], life expectancy adjustments calculated with a combined factor might actually further increase the disadvantages of a lower socio-economic position. The Norwegian pension system includes various redistributive elements [21], but some have argued that this new adoption nevertheless implies fiscal transfers from disadvantaged groups to more advantaged groups [22-24].

Studies of long-term trends provide details of the temporal variations in life expectancy differentials, which are required to determine the future burdens of these inequalities. Because inequalities are considered preventable, their elimination also represents a potentially important opportunity to improve the population's health in general $[19,25]$. Furthermore, the effects of educational inequalities on life expectancy are important for future demographic projections [26], which until now have repeatedly under-estimated the numbers of older people $[2,5,27]$. Finally, the trends in educational differences on life expectancy at the age of 65 will allow us to determine how well the overall life expectancy adjustment of annual pensions accommodates various socio-economic groups. Therefore, knowledge of these trends will make an important contribution to the debate about future pension systems.

The objective of this study was to investigate the changes in remaining life expectancy, according to educational level, for all Norwegians aged 65 years and older within the period 1961-2009.

\section{METHODS}

\section{Design and data}

We undertook a register-based population study. Statistics Norway linked data from the National Population Registry with educational data from the 1960census, and with data from the National Educational Database (NUDB) for 1970 to 2009. Educational level in the 1960s was classified according to the 1960census, and educational level after 1970 according to the NUDB. NUDB was created in 2002 and is based on self-reported data in the 1970-census and thereafter of annual administrative records of data on new achievements from all educational institutions in Norway [28].

The study population comprised the total Norwegian population aged 65 years and older for each calendar year between 1961 and 2009. We generated 49 cohorts, one for each calendar year. The cohorts were defined as all registered citizens living in Norway at any time within each year. The 1961-1970 cohorts were restricted to people registered in the 1960-census. Cases that emigrated between 1961 and 1970 were censored in 1965. Cases that emigrated between 1971 and 2009 were included every year up to the time of emigration and excluded thereafter. The cohorts were followed up for deaths occurring within the following year in Norway.

\section{Variables}

We used the remaining life expectancy at age 65 (hereafter referred to as " $e_{65}$ ") as the outcome variable. Our estimations of $e_{65}$ were based on data from the death records of the National Population Registry.

We classified education into two levels. "Lower education" was defined as compulsory primary or lowersecondary education, corresponding to the International Standard Classification of Education (ISCED97) levels 0-2 [29]. "Higher education" was defined as upper-secondary, post-secondary, or tertiary education, corresponding to ISCED97 levels 3-6. Although educational data from the 1960-census were coded differently from those in the NUDB, we were able to adjust the educational levels for the 1960 s by comparing the frequency tables of education codes for 1960 and 1970 . This adjustment was made by recoding all person years in the 1960 s according to the most frequent transitions in educational classification between the 1960s and the 1970s. This harmonization was not complete though. Of those included in the 1970 cohort, and surviving to $1971,7.6 \%$ changed their classification from less- to more educated, $4.9 \%$ changed from more- to less educated, and $86.8 \%$ did not change their educational classification in 1971. In addition, $0.8 \%$ changed to missing educational data in 1971 , and $2.5 \%$ excluded in 1970 due to missing educational data in the 1960census, were included from 1971. The educational data were almost complete for all cohorts. The mean proportion of missing data was $1.0 \%$, and the highest proportions of missing educational data were $2.4 \%$ in men in 1969-1970 and $2.7 \%$ in women in $1968-1970$.

\section{Statistical analysis}

We defined four subpopulations according to sex and educational level. For each of the subpopulations, we used mortality by one-year age groups to construct one life table, for every calendar year from 1961 to 2009. For each of these life tables, we calculated $e_{65}$ and the corresponding absolute education-based differences in $e_{65}$. Mortality was assumed to be constant beyond the age of 95 years and equal to the crude rate for the $95+$ age group [30]. We used the formula of Chiang to estimate the $95 \%$ confidence intervals for $e_{65}$ [30]. Trends in $e_{65}$ were estimated for each sex and educational group using weighted least squares regression (WLS) models in which $e_{65}$ was the outcome and calendar year the explanatory variable, and the weights were equal to the inverse variance of $e_{65}$. We tested for sex-stratified inequalities in the trends in $e_{65}$ by adding educational level and the interaction term 
Table 1. Numbers and proportions of person years and deaths, by sex, educational level, and period, in men and women aged 65 years and above and residing in Norway, in 1961-2009. "Lower education" is defined as compulsory primary or lower-secondary education, corresponding to the ISCED97 levels 0-2. "Higher education" is defined as upper-secondary, post-secondary, or tertiary education, corresponding to ISCED97 levels 3-6 (ISCED97 = International Standard Classification of Education 1997) [29]. Proportion of missing educational data (total, both sexes): $1.0 \%$.

\begin{tabular}{|c|c|c|c|c|c|c|c|c|c|c|c|c|c|}
\hline \multirow[b]{3}{*}{ Person years } & \multirow{3}{*}{$\begin{array}{l}\text { Educational } \\
\text { level }\end{array}$} & \multicolumn{10}{|c|}{ Period } & \multirow{2}{*}{\multicolumn{2}{|c|}{ Total }} \\
\hline & & \multicolumn{2}{|c|}{ 1961-1970 } & \multicolumn{2}{|c|}{$1971-1980$} & \multicolumn{2}{|c|}{$1981-1990$} & \multicolumn{2}{|c|}{ 1991-2000 } & \multicolumn{2}{|c|}{$2001-2009$} & & \\
\hline & & $\mathrm{n}$ & $\%$ & $\mathrm{n}$ & $\%$ & $\mathrm{n}$ & $\%$ & $\mathrm{n}$ & $\%$ & $\mathrm{n}$ & $\%$ & $\mathrm{n}$ & $\%$ \\
\hline \multirow[t]{4}{*}{ Men } & & & & & & & & & & & & & \\
\hline & Lower & 1448211 & 74 & 1558719 & 66 & 1585638 & 58 & 1383335 & 48 & 995219 & 38 & 6971123 & $\begin{array}{l}56 \\
44\end{array}$ \\
\hline & Higher & 510002 & 26 & 803839 & 34 & 1151761 & 42 & 1472340 & 52 & 1597398 & 62 & 5535340 & 44 \\
\hline & Total & 1958213 & 100 & 2362558 & 100 & 2737400 & 100 & 2855675 & 100 & 2592616 & 100 & 12506463 & 100 \\
\hline \multirow[t]{3}{*}{ Women } & $\mathrm{L}$ & 2051506 & 83 & & 73 & & 67 & 24076 & 60 & 17800 & 50 & 11071991 & 65 \\
\hline & Higher & 410373 & 17 & 858462 & 27 & 1245739 & 33 & 1611595 & 40 & 1751623 & 50 & 5877793 & 35 \\
\hline & Total & 2461879 & 100 & 3145019 & 100 & 3791902 & 100 & 4019280 & 100 & 3531703 & 100 & 16949784 & 100 \\
\hline \multirow[t]{3}{*}{ Both sexes } & & & & & & & 63 & & 55 & & 45 & & \\
\hline & $\begin{array}{l}\text { Lower } \\
\text { Higher }\end{array}$ & 920375 & 21 & 1662301 & 30 & 2397500 & $\begin{array}{l}03 \\
37\end{array}$ & 3083935 & 45 & 3349021 & $\begin{array}{l}45 \\
55\end{array}$ & 11413133 & $\begin{array}{l}01 \\
39\end{array}$ \\
\hline & Total & 4420092 & 100 & 5507577 & 100 & 6529302 & 100 & 6874955 & 100 & 6124319 & 100 & 29456247 & 100 \\
\hline \multicolumn{14}{|l|}{ Deaths } \\
\hline \multicolumn{14}{|l|}{ Men } \\
\hline & Lower & 96783 & 78 & 107798 & 71 & 111902 & 64 & 101405 & 57 & 70099 & 49 & 487987 & 63 \\
\hline & Higher & 27566 & 22 & 44903 & 29 & 62712 & 36 & 77144 & 43 & 74334 & 51 & 286659 & 37 \\
\hline & Total & 124349 & 100 & 152701 & 100 & 174614 & 100 & 178549 & 100 & 144433 & 100 & 774646 & 100 \\
\hline \multirow{4}{*}{ Women } & & & & & & & & & & & & & \\
\hline & Lower & 110027 & 89 & 118576 & 80 & 126993 & 73 & 131797 & 68 & 105707 & 62 & 593100 & 73 \\
\hline & Higher & 14072 & 11 & 30375 & 20 & 46976 & 27 & 62882 & 32 & 65418 & 38 & 219723 & 27 \\
\hline & Total & 124099 & 100 & 148951 & 100 & 173969 & 100 & 194679 & 100 & 171125 & 100 & 812823 & 100 \\
\hline \multirow[t]{4}{*}{ Both sexes } & & & & & & & & & & & & & \\
\hline & Lower & 206810 & 83 & 226374 & 75 & 238895 & 69 & 233202 & 62 & 175806 & 56 & 1081087 & 68 \\
\hline & Higher & 41638 & 17 & 75278 & 25 & 109688 & 31 & 140026 & 38 & 139752 & 44 & 506382 & 32 \\
\hline & Total & 248448 & 100 & 301652 & 100 & 348583 & 100 & 373228 & 100 & 315558 & 100 & 1587469 & 100 \\
\hline
\end{tabular}

education by year to the model specified above. The interaction terms were interpreted as the mean absolute yearly changes in the differences in $e_{65}$. We tested for the overall trends from 1961 to 2009 and separately for sub-trends in each of five periods: 1961-1970, 19711980, 1981-1990, 1991-2000, and 2001-2009.

To compare the overall life expectancy with the group-specific life expectancies, we also constructed a joint life table for both sexes and both educational groups together, based on mortality rates according to one-year age groups.

We regarded two-sided $\mathrm{P}$ values of $<0.05$ to be statistically significant and used Stata/IC 12.0 (StataCorp LP, College Station, TX, USA, 2012) to construct the life tables, for the statistical analyses, and to create graphics.

\section{RESULTS}

The study population included 29,456,247 person years and 1,587,469 deaths in the period 1961-2009 for ages 65 and above (Table 1). The proportion of person years with lower education decreased from $74 \%$ to $38 \%$ for men and from $83 \%$ to $50 \%$ for women between the 1960 s and the years after 2000 (Table 1).

Among men, $e_{65}$ increased from 14.8 to 16.8 years in the less-educated and from 15.7 to 19.0 years in the more-educated between 1961 and 2009 (Figure 1).
The weighted mean yearly increase in $e_{65}$ from 1961 to 2009 was 0.045 life years per calendar year for less-educated men $(\mathrm{P}<0.001)$ and 0.105 life years per calendar year in more-educated men $(\mathrm{P}<0.001$; Figure 2). However, the pace and pattern of change was not constant. During the first decade, $e_{65}$ declined in both educational groups $(\mathrm{P}<0.001)$, whereas from 1970 onwards, $e_{65}$ seemed to increase at an accelerating rate. Since 2001 , this rate has been 0.173 life years per calendar year for less-educated men ( $\mathrm{P}<$ $0.001)$ and 0.207 life years per calendar year for moreeducated men $(\mathrm{P}<0.001$; Figure 2$)$.

The smaller increase in $e_{65}$ among less-educated men led to an increasing education-based difference in $e_{65}$ over the observation period (Figure 3 ). These differences were statistically significant from about 1990 onwards (Figure 3). The sub-trend analysis revealed that the differences increased significantly through the $1980 \mathrm{~s}(\mathrm{P}=0.035)$ and 1990s $(\mathrm{P}=0.016$; Figure 4). Overall, education-based differences in $e_{65}$ increased by 0.060 life years per calendar year between 1961 and 2009 ( $<<0.001$; Figure 4).

Among women, $e_{65}$ increased from 16.8 to 20.5 years in the less-educated and from 18.1 to 23.0 years in the more-educated between 1961 and 2009 (Figure $1)$. The weighted mean yearly increase in $e_{65}$ from 1961 to 2009 was 0.088 life years per calendar year for less-educated women $(\mathrm{P}<0.001)$ and 0.113 life years 


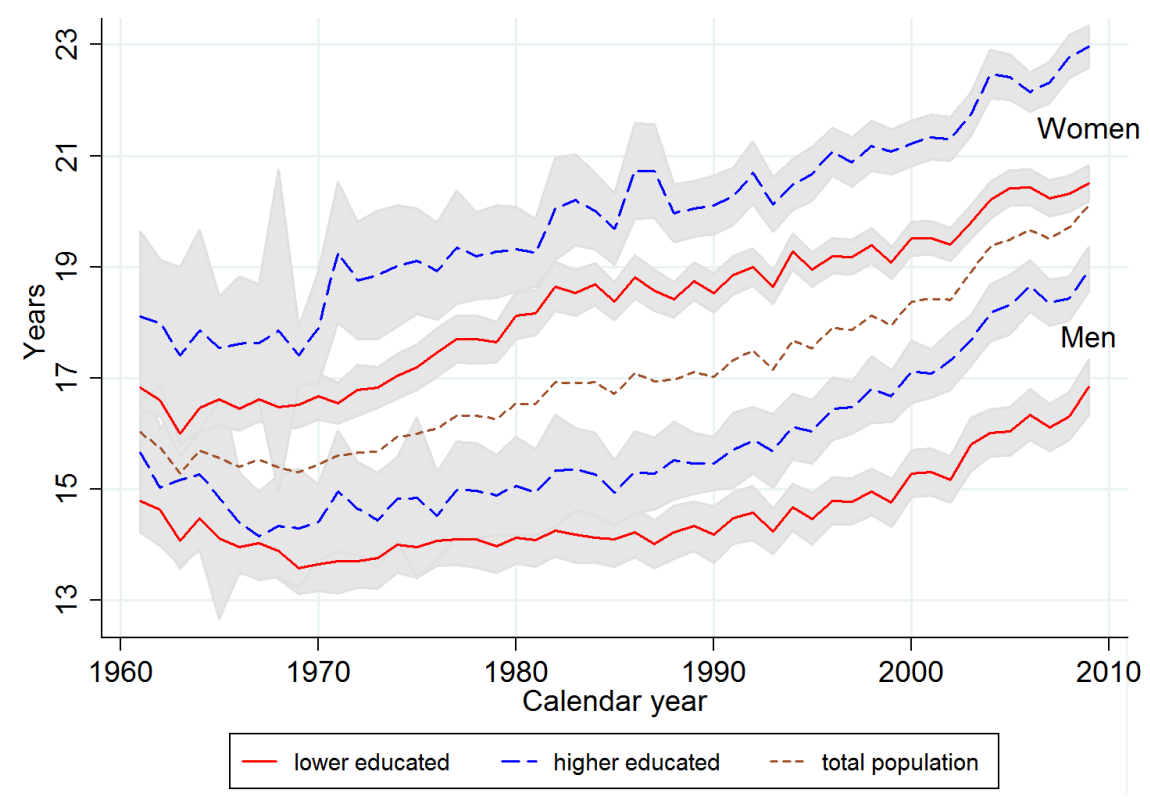

Figure 1. Remaining life expectancy at age $65\left(e_{65}\right)$ by educational level, men and women, 1961-2009. Shaded area represents $95 \%$ confidence interval. The dotted line in the middle represents the overall figures for the population as a whole.

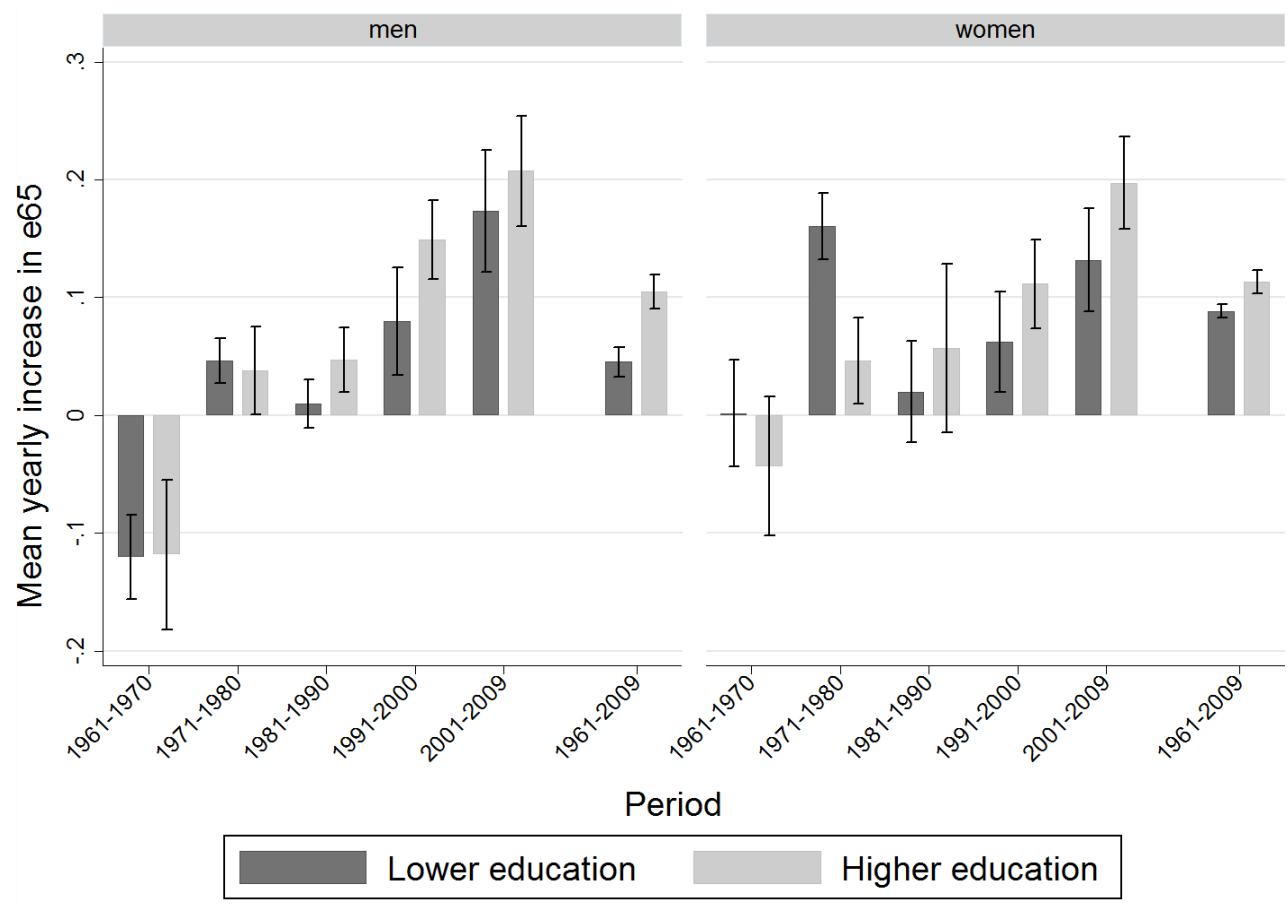

Figure 2. Weighted mean yearly change in $e_{65}$ by educational level and period, 1961-2009. Trends for five subperiods and overall trend (1961-2009). Men and women. 95\% confidence interval. Estimated by WLS-regression models stratified by sex and educational level, where $e_{65}$ is explained by calendar year.

per calendar year for more-educated women $(\mathrm{P}<$ 0.001 ; Figure 2). The rate of increase was more constant throughout this period in women than in men, and no decade showed a significant decline in $e_{65}$. As in men, $e_{65}$ seems to have increased at an accelerating rate from the 1970s onwards. Since 2001, the rate has been 0.132 life years per calendar year in less-educated women $(\mathrm{P}<0.001)$ and 0.197 years per calendar year in more-educated women $(\mathrm{P}<0.001$; Figure 2$)$.
Education-based differences in $e_{65}$ have also tended to increase. Except for a short period at the beginning of the 1970s, education-based differences in $e_{65}$ have increased and these differences were significant from about 1985 onwards (Figure 3). The sub-trend analysis revealed that these differences declined significantly in the 1970s, whereas they tended to increase later. Since 2001, the increase in the differences in $e_{65}$ has been significant $(\mathrm{P}=0.029$; Figure 4$)$. Overall, education- 


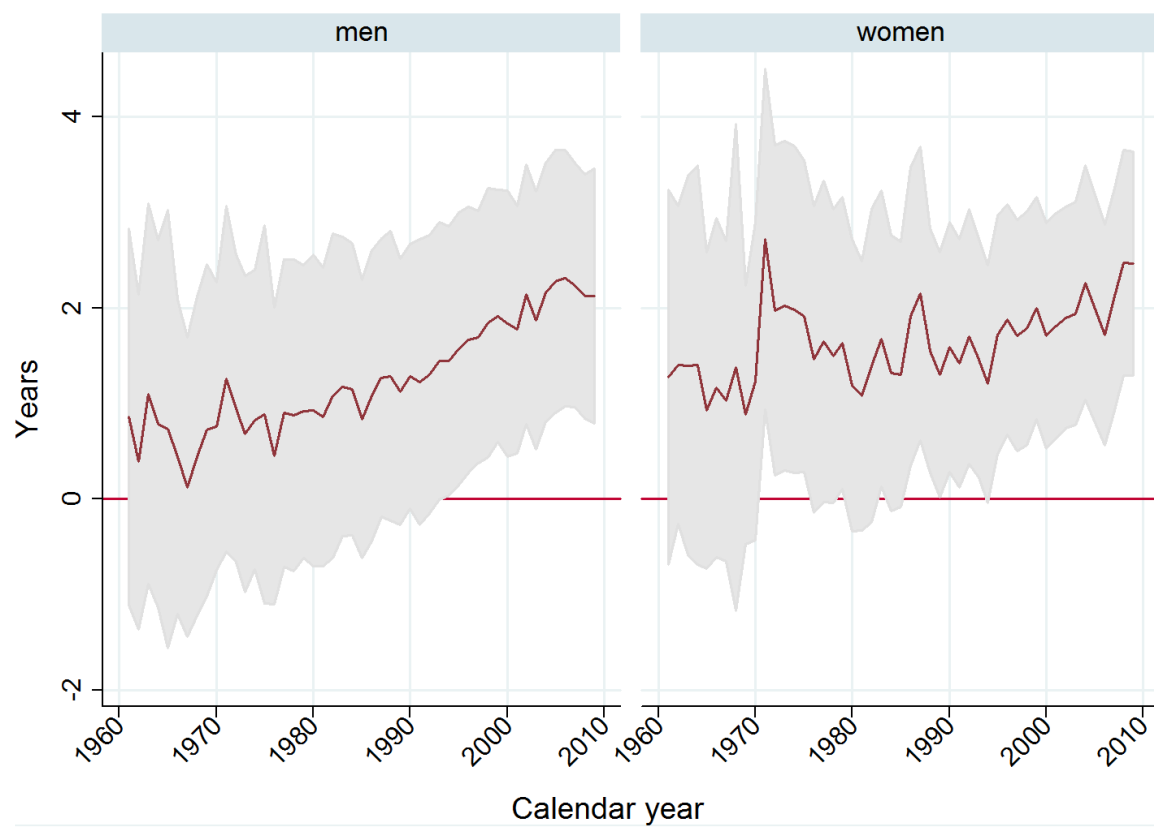

Figure 3. Absolute education-based differences in $e_{65}$ between more and less-educated, 1961-2009. Men and women. Shaded area represents $95 \%$ confidence interval.

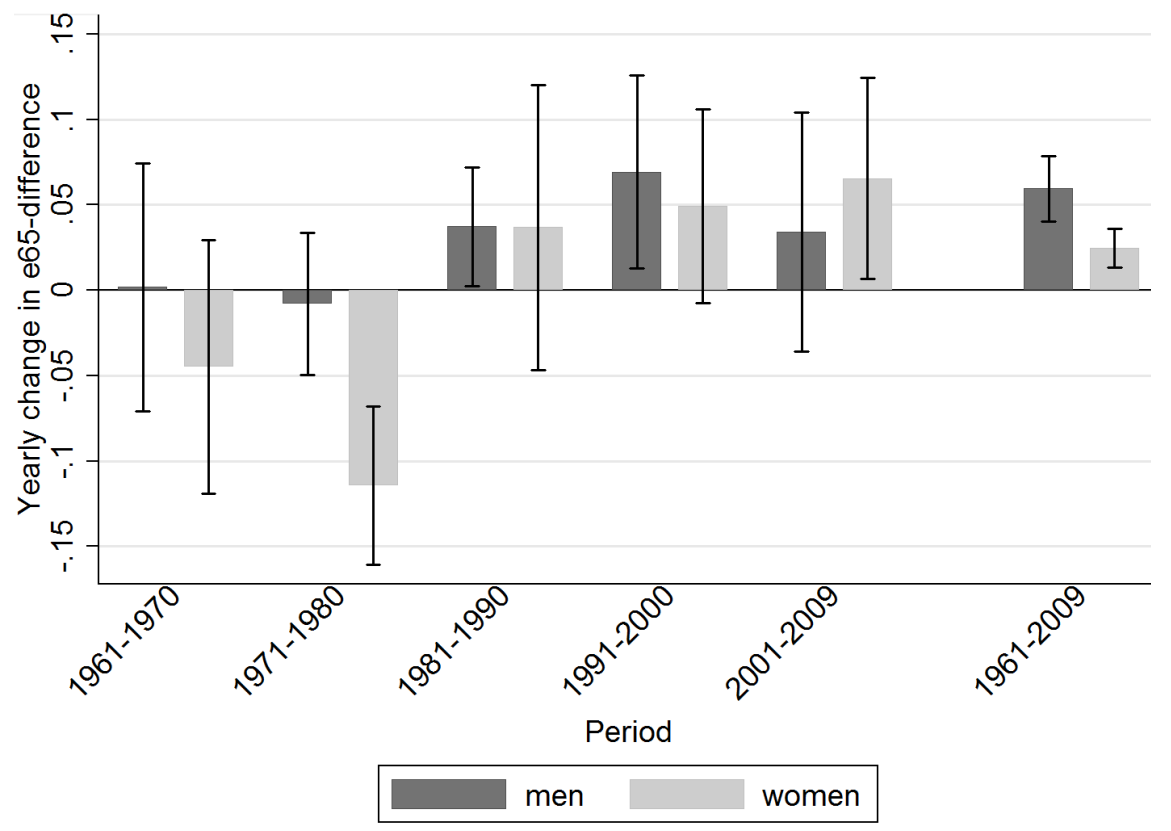

Figure 4. Weighted mean yearly change in education-based differences in $e_{65}, 1961-2009$. Trends for five sub-periods and overall trend (1961-2009). Men and women. 95\% confidence interval. Estimated by WLS-regression models stratified by sex, where $e_{65}$ is explained by the main effects and interaction effects of calendar year and educational level.

based inequalities in $e_{65}$ increased by 0.025 life years per calendar year between 1961 and $2009(\mathrm{P}<0.001$; Figure 4).

\section{Relationship between subgroup-specific $e_{65}$ and overall $e_{65}$ for the whole population}

With the exception of the $1960 \mathrm{~s}$, men had a lower $e_{65}$ and women a higher $e_{65}$ than the overall $e_{65}$ for the population as a whole (Figure 1). The increase in $e_{65}$ was slower in men in the 1970s and 1980s than the increase in the overall $e_{65}$ (Figures 1). Whereas the rate of $e_{65}$ increase in more-educated men approximated the increase in the overall $e_{65}$ at the end of the $1980 \mathrm{~s}$, the rate of $e_{65}$ increase in less-educated men did not catch up until after 2000 (Figure 1). The increase in $e_{65}$ among lesseducated women seems to have been slower than the increase in $e_{65}$ for the whole population throughout the entire period examined, except in the 1970s (Figure 1). 


\section{DisCUSSION}

Overall, $e_{65}$ increased in men and women between 1961 and 2009. This increase was greatest among more-educated. Education-based inequalities in $e_{65}$ increased in both sexes, albeit somewhat more markedly in men. The $e_{65}$ of men decreased in the $1960 \mathrm{~s}$, before a long and still ongoing period of accelerated increase from the 1970s. However, during much of the $1970 \mathrm{~s}$ and $1980 \mathrm{~s}$ this rate of acceleration in $e_{65}$ was slower in less-educated men behind their more educated counterparts, causing the education-based inequalities in $e_{65}$ to increase. From 2000 onwards, the rate of increase in $e_{65}$ among less-educated men approximated the rate among more-educated men, and the gap in $e_{65}$ stabilized. In women, $e_{65}$ increased more steadily throughout the period than in men. From 1980 onwards, the increase in $e_{65}$ in less-educated women seems to have decelerated and the difference in $e_{65}$ between less- and more-educated women has increased, although this increase was only statistically significant in the period 2001-2009.

\section{Strengths and limitations}

This study had several strengths. First, it included the total Norwegian population aged 65 years and older, and there were very few missing cases. Second, it covered a long period of almost half a century, and thereby mapped large changes in society, with the establishment of the welfare state and strong economic growth [31]. Third, by estimating life expectancies in one-year periods, we described more nuances in the changes in the education-based inequalities in $e_{65}$ than have been reported previously among older persons.

We also note some limitations of this study. First, the change in the data source for educational levels between the 1960s and thereafter may have generated some misclassification bias. We sought to reduce this potential bias by adjusting the educational levels used in the 1960 s to the classification used after 1970 . However, systematic adjustment errors may have led to conservative estimates of differences in $e_{65}$ during the 1960s which would lead to overestimation of the overall trends. Nevertheless, the sub-trends after 1970 would not have been affected, and the overall trends from 1971 to 2009 would yield the same conclusions of increasing inequalities in $e_{65}$. The extent of any potential misclassification bias was reduced by our compression of the educational hierarchy into only two strata.

Another issue of concern is the use of educational levels as a socio-economic determinant. Educational level has been shown to be an important health determinant in old age [32-34]. However, its distribution is highly skewed in older populations. The oldest old in our population were born in the second part of the 19th century. At that time, Norway reformed the school system and merged the class-stratified schools of the working-, middle, and upper class into one common school system [35,36], to ensure that anyone could achieve higher education, independent of social position. However, large social and geographic differences in educational opportunities persisted for several decades $[35,36]$. The limited extent of differentiation by educational levels was another reason for compressing the educational hierarchy into two strata.

Finally, whereas the records of educational level were self-reported in the 1960s and the 1970-census, updated data have been collected directly from educational institutions thereafter. Thus, as most of the study population had probably finished their education prior to 1970 , most of the educational level data was selfreported. Although this could be a source of misclassification bias due to inaccurate self-reporting, the direction of this bias is unclear, and we consider it unlikely to have substantially biased the trends.

\section{Comparison with previous studies}

The increases in $e_{65}$ revealed in our study resemble the increases in life expectancy at age $35\left(e_{35}\right)$ in Norway, reported by Steingrímsdóttir et al. in their analysis based on the same data source [13]. The slower increase in $e_{65}$ in less-educated men in the 1980s and $1990 \mathrm{~s}$ and the decelerated increase in $e_{65}$ in the lesseducated women from the 1980s onwards were also observed in $e_{35}$ in their study. These similar patterns of changes occur because the educational differences in increases in survival probabilities between 1961 and 2009 were much larger among people aged 65 and above than among those aged 35 to 64 [13].

We do not know of any other study of the trends in education-based inequalities in life expectancy among older adults covering more than two decades. Our subtrend results are consistent with the results of shortertrend studies. The education-based inequalities in $e_{65}$ increased in both sexes in Belgium between 1991 and 2001 [4] and in the USA between 1970 and 1990 [14]. In Sweden, education-based inequalities in $e_{65}$ increased among non-manual workers, whereas they declined among manual workers between 1980 and 1997 [15]. Trends in life expectancy among older adults have also been studied according to other socio-economic health determinants. Inequalities in $e_{65}$ between the leastdeprived and most-deprived socio-economic counties in the USA increased between 1980 and 2000 [8]. According to Finnish data provided by Martikainen et al. [7], the gap in $e_{65}$ between manual and non-manual workers increased in both sexes between 1971 and 1995, and the largest increase was during the 1980s.

Most of the increases in life expectancy at birth $\left(e_{0}\right)$ are now increasingly driven by declining mortality among those in higher age groups $[3,4]$. Therefore, it is also tempting to compare our results with trends in best-practice life expectancy: i.e., the highest national value recorded in the world, as presented by Oeppen and Vaupel in Science in 2002 [2]. They found that in the record-holding countries, $e_{0}$ rose for 160 years at a steady rate of 0.243 life years per calendar year in 
women and 0.222 life years per calendar year in men. According to our analysis, the accelerated increase in $e_{65}$ in Norway now approximates the rate of increase in $e_{0}$ in the record-holding countries.

The increases in $e_{65}$ after 2000 seen in our analysis also exceed the current projections of $e_{0}$ towards 2100 by Statistics Norway, which stipulated an increase of about 0.12 life years per calendar year in men and 0.10 life years per calendar year in women [37].

\section{Explanation and interpretation of our results}

Trends in mortality rates among older adults are not only the main explanation for the recent increases in life expectancies at birth and young ages, but also the main explanation for the increases in education-based differences in life expectancies [4,13]. Most deaths occur among older people [11,33], and consequently, education-based differences in old-age mortality are the main driver behind the education-based differences in life expectancy in younger age groups [4]. This illustrates the importance of using absolute inequalities in mortality rates to evaluate public health in addition to relative inequalities. Although the large and increasing relative socio-economic-based inequalities in mortality found among younger age groups are important challenges for health policy, it is the difference in absolute risk that affects the life expectancy differentials.

Explaining trends in $e_{65}$ was beyond the scope of this paper and the long lives lived of our study population make it challenging to disentangle particular causes behind the trends. For instance, the variation in causes of death increases with higher ages [38], and contrary to younger age groups, old age mortality is not restricted to high risk individuals, and it results from more complex states of coexisting diseases [38].

Despite the complexity of inequalities in older ages, some general theories are nevertheless interesting [3941]. Social conditions might be fundamental causes of ill-health, mediated by shifting mechanisms throughout the period $[42,43]$ which accumulate over the life course. The possible mechanisms include educationbased inequalities in environmental and occupational hazards, absolute and relative deprivation, cultural capital and behavior [39-41]. The higher educationgroup might have been faster in recognizing new health-enhancing knowledge and interventions, and they might have been more able to benefit from them through behavior change [43-45].

All of these mechanisms might contribute in explaining why inequalities exist [39]. Nevertheless, in order to explain the temporal widening in $e_{65}$, and also the sex-differences in trends, the mechanisms must have been related to major lethal risk factors that changed in impact or educational distribution over time. Causespecific mortality rates might provide some clues. In middle aged populations, and especially among men, cardiovascular mortality has been the main cause of increasing socio-economic-based inequalities in morta- lity $[46,47]$. A frequently suggested explanation has been the tobacco epidemic $[45,48,49]$. Educationbased inequalities in tobacco use are still increasing, and these increases vary between men and women [48, 50], which might partly explain the trends we found $[39,43,51]$. The delayed and lower uptake of tobacco use among women compared with men may explain the weaker increase in $e_{65}$ among less-educated women from the 1980 s and thereafter.

Another often mentioned factor is compositional changes in the social strata. While the educational opportunities of the oldest birth cohorts depended more on family background, the welfare state has aimed at providing equal opportunities for all. As others have suggested, the following expansion of higher education might have resulted in a stronger socially differentiation of material and immaterial resources in younger birth cohorts $[4,7,39,47]$. An education-based polarization of immaterial resources like cultural capital and personal characteristics could be of particular importance by influencing ability and motivation to behavior change [39]. Although the delayed increase in educational attainment among women could explain the sex-differences in trends in $e_{65}$, we consider the extent of compositional changes to be somewhat limited in our study as the lower educational group was large throughout the study period. Further, compositional changes cannot explain why inequalities in $e_{65}$ among men seemed to stabilize after 2000 .

\section{Implications of our results}

Research in preventive medicine and demography has shown that even in older ages, mortality is amenable to interventions $[52,53]$. Thus, old age inequalities represent an unexploited potential to public health which will become increasingly important as many countries are facing aging populations.

Our findings might also have implications for national population forecasts. In the current "middle alternative" forecast by Statistics Norway, mortality is assumed to decline further by about the same rate as has been observed since the 1950s. These assumptions will lead to $e_{0}$ in 2100 of about 89.5 years in men and 92.5 years in women [37], corresponding to a mean rate of increase of 0.12 life years/calendar year in men and 0.10 life years/calendar year in women. Our findings suggest that the increases in $e_{65}$ have recently accelerated beyond these levels in all educational strata. It is too early to tell whether this trend will persist, but historically, demographic projections have systematically under-estimated the number of older people [2, 26,27]. A possible reason for this is that the projections do not take into account the increases in the level of education in the population [26].

The differences in $e_{65}$ between the sexes, the two educational groups, and the population as a whole reflect the group-specific fit of the joint life-expectancy adjustment of pension levels. Men, and especially lesseducated men, will receive lower pensions than the 
group-specific life expectancy indicates. On the contrary, more-educated women will receive higher annual pensions than is indicated by the group-specific life expectancy. This effect can be illustrated by the relative deviations of the group-specific $e_{65}$ values from the overall $e_{65}$ for the population as a whole. The $e_{65}$ values for less- and more-educated men were $16 \%$ (3.28 years) and 6\% (1.16 years) lower than the overall $e_{65}$, respectively, in 2009 . The corresponding values for less- and more-educated women were $2 \%(0.38$ years) and $14 \%$ (2.85 years) higher than the overall $e_{65}$, respectively. Thus, if the pension reform had been fully implemented in 2009, less- and more-educated men retiring at age 65 would have received annual pensions $16 \%$ and $6 \%$ lower, respectively, than if the method of life expectancy adjustment had taken sex and educational level into account. In contrast, lessand more-educated women would have received annual pensions $2 \%$ and $14 \%$ higher, respectively, under the same system. The increases in education-based inequalities in $e_{65}$ might lead to even larger discrepancies between group-specific life expectancies and overall life expectancies in the future. Nevertheless, pension levels are determined by complex calculations [21]. Thus the seemingly favoring of more-educated women compared to less-educated men due to life expectancy adjustment by unisex factors is moderated by several factors, including sex differences in working life history, and the inversely relation between pension replacement rates and individual earnings [5,21].

\section{Conclusions}

Life expectancy at age $65\left(e_{65}\right)$ has increased over the last half century, and this increase has been accelerating in recent decades. However, the increase has been smaller for less-educated people than for more- educated people, so that the education-based differences in $e_{65}$ have increased. Our study shows that increasing education-based inequalities in old-age mortality are the main causes of the increasing inequalities in life expectancies in younger age groups. These increasing inequalities in $e_{65}$ are challenges for public health policy but represent nevertheless a significant opportunity to improve the population's health. In addition, inequalities in life-expectancy have become even more relevant in the light of the recently implemented lifeexpectancy-based adjustment of annual old-age pensions. Our findings of educational-based divergent trends in $e_{65}$ might also have implications for demographic projections in the future.

\section{ACKNOWLEDGEMENTS}

We thank Statistics Norway for providing us with data and Kåre Bævre at the Norwegian Institute for Public Health for preparing the data for analysis and for valuable discussions. We also thank Terje P. Hagen and the seminar participants at the University of Oslo and the Norwegian Institute of Public Health for their valuable comments on the manuscript.

\section{ETHICAL APPROVAL}

The study was approved by the Regional Committee for Medical and Health Research Ethics, South-East Norway (approval number 2010/260).

\section{COMPETING INTERESTS}

The authors declare no competing interests.

\section{FUNDING SOURCES}

This study was funded by the Norwegian Institute of Public Health and the University of Oslo. The funding bodies had no role in the study design; collection, analysis, or interpretation of the data; writing of the report; or the decision to submit the article for publication.

\section{REFERENCES}

1. Robine J-M, Michel J-P. Looking forward to a general theory on population aging. J Gerontol A Biol Sci Med Sci 2004, 59A (6): 590-597.

2. Oeppen J, Vaupel JW. Broken limits to life expectancy. Science 2002, 296 (5570): 1029-1031.

3. Christensen K, Doblhammer G, Rau R, Vaupel JW. Ageing populations: the challenges ahead. Lancet 2009, 374 (9696): 1196-1208.

4. Deboosere P, Gadeyne S, Van Oyen H. The 1991-2004 evolution in life expectancy by educational level in Belgium based on linked census and population register data. Eur J Popul 2009, 25 (2): 175-196.

5. OECD. Pensions at a Glance 2011: Retirement-Income Systems in OECD and G20 Countries, 2011 [www.oecd.org/els/social/pensions/PAG].

6. Majer IM, Nusselder WJ, Mackenbach JP, Kunst AE. Socioeconomic inequalities in life and health expectancies around official retirement age in 10 Western-European countries. J Epidemiol Community Health 2011, 65 (11): 972-979.

7. Martikainen P, Valkonen T, Martelin T. Change in male and female life expectancy by social class: decomposition by age and cause of death in Finland 1971-95. J Epidemiol Community Health 2001, 55 (7): 494-499.

8. Singh GK, Siahpush M. Widening socioeconomic inequalities in US life expectancy, 1980-2000. Int J Epidemiol 2006, 35 (4): 969-979.

9. Martelin T, Koskinen S, Valkonen T. Sociodemographic mortality differences among the oldest old in Finland. J Gerontol B-Psychol 1998, 53B (2): S83-S90. 
10. Marmot MG, Shipley MJ. Do socioeconomic differences in mortality persist after retirement? 25 year follow up of civil servants from the first Whitehall study. BMJ 1996, 313 (7066): 1177-1180.

11. Huisman M, Kunst AE, Andersen O, Bopp M, Borgan JK, Borrell C, et al. Socioeconomic inequalities in mortality among elderly people in 11 European populations. J Epidemiol Community Health 2004, 58 (6): 468-475.

12. Brønnum-Hansen H, Baadsgaard M. Increasing social inequality in life expectancy in Denmark. Eur J Public Health 2007, 17 (6): 585-586.

13. Steingrímsdóttir ÓA, Næss Ø, Moe JO, Grøholt E-K, Thelle D, Strand BH, et al. Trends in life expectancy by education in Norway 1961-2009. Eur J Epidemiol 2012, 27 (3): 163-171.

14. Crimmins EM, Saito Y. Trends in healthy life expectancy in the United States, 1970-1990: gender, racial, and educational differences. Soc Sci Med 2001, 52 (11): 1629-1641.

15. Burström K, Johannesson M, Diderichsen F. Increasing socio-economic inequalities in life expectancy and QALYs Sweden 1980-1997. Health Econ 2005, 14 (8): 831-850.

16. Det Kongelige arbeids- og inkluderingsdepartement. Ot. prp. nr. 37 Om lov om endringer i folketrygdloven (ny alderspensjon); 2008-2009 [http://www.regjeringen.no/pages/2152932/PDFS/OTP200820090037000 DDDPDFS.pdf].

17. Veland G, Bratland K. Levealdersjustering i kommunal tjenestepensjon. Fafo-report 2008: 12; 2008 [http://www.fafo.no/pub/rapp/20054/index.html].

18. World Health Organization. Regional office for Europe. Socioeconomic determinants [http://www.euro.who. int/en/what-we-do/health-topics/health-determinants/socioeconomic-determinants].

19. Elstad JI. Social inequalities in health and their explanations. Dr. Philos. thesis, University of Oslo, 2000 [http://www.nova.no/id/524.0].

20. Whitehead M, Dahlgren G. Concepts and principles for tackling social inequalities in health. Levelling up (part 1). Studies on social and economic determinants of population health no. 2. Copenhagen, Denmark: World Health Organization Regional Office for Europe; 2006 [http://www.euro.who.int/en/what-wedo/health-topics/health-determinants/social-determinants/publications/concepts-and-principles-for-tacklingsocial-inequalities-in-health].

21. Stensnes K, Stølen NM, Texmon I. Pensjonsreformen: Virkninger på statsfinanser, effektivitet og fordeling. Reports 2007/11: Statistics Norway, 2007 [http://www.ssb.no/emner/12/01/rapp_200711/rapp_200711.pdf].

22. Lunde H, Bjørnås SI. Mener pensjonsreformen er grunnleggende urettferdig. NRK.no, 03.11.2010 [http:// www.nrk.no/nyheter/norge/1.7364808].

23. Westin S. Pensjonsreform for større ulikhet? Dagbladet 15.02.2007 [http://www.dagbladet.no/kultur/2007/ 02/15/492066.html].

24. Stensnes K, Stølen NM. Pensjonsreformens fordelingsprofil. Dagbladet 11.03.2007 [http://www.dagbladet. no/kultur/2007/03/11/494604.html].

25. Mackenbach JP, Kunst AE. Measuring the magnitude of socio-economic inequalities in health: an overview of available measures illustrated with two examples from Europe. Soc Sci Med 1997, 44 (6): 757-771.

26. Batljan I, Thorslund M. The effect of change in educational composition on population ageing. Eur J Ageing 2009, 6 (3): 191-200.

27. Keilman N, Dihn QP. Hvor lenge kommer vi til å leve? Levealder og aldersmønster for dødeligheten i Norge, 1900-2060. In: Økonomiske analyser (Statistisk sentralbyrå), 2005: 43-49.

28. Statistics Norway. Individually based education statistics. Documentation 2005 [http://www.ssb.no/english/ subjects/04/90/nos_d361_en/nos_d361_en.pdf].

29. International standard classification of education. ISCED 1997 [http://www.unesco.org/education/ information/nfsunesco/doc/isced_1997.htm].

30. Chiang CL. The life table and its applications. Malabar, Fla.: Robert E. Krieger Publishing Company, 1984.

31. The economic history of Norway [http://eh.net/encyclopedia/article/grytten.norway].

32. Rostad B, Deeg DJH, Schei B. Socioeconomic inequalities in health in older women. Eur J Ageing 2009, 6 (1): 39-47.

33. Arber S, Ginn J. Gender and inequalities in health in later life. Soc Sci Med 1993, 36 (1): 33-46.

34. Grundy E, Holt G. The socioeconomic status of older adults: How should we measure it in studies of health inequalities? J Epidemiol Community Health 2001, 55 (12): 895-904.

35. Baune TA. Den skal tidlig krøkes: skolen i historisk perspektiv. Oslo: Cappelen akademisk forlag, 1995.

36. Myhre R. Den norske skoles utvikling. Oslo: Ad notam Gyldendal, 1998.

37. Brunborg H, Texmon I, Tønnesen M. Befolkningsframskrivninger 2012-2100: Modell og forutsetninger. Økonomiske analyser 2012 (4).

38. Horiuchi S. Causes of death among the oldest-old: age-related changes in the cause-of-death distribution. In: Human Longevity, Individual Life Duration, and the Growth of the Oldest-Old Population. Robine J-M, Crimmins EM, Horiuchi S, Yi Z (eds.). Amsterdam: Springer, 2006: 215-235. 
39. Mackenbach JP. The persistence of health inequalities in modern welfare states: The explanation of a paradox. Soc Sci Med 2012, 75 (4): 761-769.

40. Bambra C. Health inequalities and welfare state regimes: theoretical insights on a public health 'puzzle'. $J$ Epidemiol Community Health 2011, 65 (9): 740-745.

41. Huijts T, Eikemo TA. Causality, social selectivity or artefacts? Why socioeconomic inequalities in health are not smallest in the Nordic countries. Eur J Public Health 2009, 19 (5): 452-453.

42. Link BG, Phelan J. Social conditions as fundamental causes of disease. J Health Soc Behav 1995, 35: 80-94.

43. Link BG, Phelan J. The social shaping of health and smoking. Drug Alcohol Depend 2009, 104: S6-S10.

44. Victora CG, Vaughan JP, Barros FC, Silva AC, Tomasi E. Explaining trends in inequities: evidence from Brazilian child health studies. Lancet 2000, 356 (9235): 1093-1098.

45. Lopez AD, Collishaw NE, Piha T. A descriptive model of the cigarette epidemic in developed countries. Tob Control 1994, 3 (3): 242-247.

46. Strand BH, Grøholt E-K, Steingrímsdóttir ÓA, Blakely T, Graff-Iversen S, Næss Ø. Educational inequalities in mortality over four decades in Norway: prospective study of middle aged men and women followed for cause specific mortality, 1960-2000. BMJ 2010, 340: c654.

47. Mackenbach JP, Bos V, Andersen O, Cardano M, Costa G, Harding S, et al. Widening socioeconomic inequalities in mortality in six Western European countries. Int J Epidemiol 2003, 32 (5): 830-837.

48. Cavelaars AEJM, Kunst AE, Geurts JJM, Crialesi R, Grötvedt L, Helmert U, et al. Educational differences in smoking: international comparison. BMJ 2000, 320 (7242): 1102-1107.

49. Mackenbach JP, Stirbu I, Roskam A-JR, Schaap MM, Menvielle G, Leinsalu M, et al. Socioeconomic inequalities in health in 22 European countries. N Engl J Med 2008, 358 (12): 2468-2481.

50. Rønneberg A, Lund KE, Hafstad A. Lifetime smoking habits among Norwegian men and women born between 1890 and 1974. Int J Epidemiol 1994, 23 (2): 267-276.

51. Houweling TAJ, Kunst AE, Huisman M, Mackenbach JP. Using relative and absolute measures for monitoring health inequalities: experiences from cross-national analysis on maternal and child health. Int $J$ Equity Health 2007, 6 (1): 15.

52. Vaupel JW, Carey JR, Christensen K. It's never too late. Science 2003, 301 (5640): 1679-1681.

53. Goldberg TH, Chavin SI. Preventive medicine and screening in older adults. J Am Geriatr Soc 1997, 45 (3): 344-354. 